\title{
PREVALENCE OF MUSCULOSKELETAL DISORDERS IN WORKERS IN AN INDUSTRY IN AHMEDNAGAR DISTRICT, MAHARASHTRA
}

\author{
Sneha Chordiya ${ }^{1}$, Nitin Nikhade ${ }^{2}$ \\ ${ }^{1}$ Assistant Professor, Department of Cardio-respiratory Physiotherapy, \\ Anand Rishiji Hospital and Medical Research Center, Ahmednagar, Maharashtra. \\ ${ }^{2}$ Professor, Department of Community Physiotherapy, \\ MAEER'S Physiotherapy College, Talegaon Dabhade, Pune, Maharashtra, India.
}

\begin{abstract}
Introduction: Musculoskeletal disorders are a major public health problem in industrialized and developing countries. The present study was aimed to find out the prevalence of acute and chronic WMSD's in Industrial workers. Methodology: This cross-sectional observational study was carried out in 60 workers of the Adon Block department workers of the electrical \& automation industry, Ahmednagar. Pre-structured occupational Performa was filled by asking questions in the worker's local language. The Nordic pain Questionnaire was filled by asking the subjects to mark the sites of pain on body chart paper. The risk factors for work-related musculoskeletal problems were assessed by the working posture of workers and repetitive movements in industrial set up. The data collected were interpreted and analyzed. Results: In the present study, 60 workers were selected, of which a number of females were $39(65 \%)$ while males were $21(35 \%)$. The Neck (20.2\%) followed by the shoulder (14.9\%), elbow (14.4\%) and knee (14.4\%) were most commonly involved. There was a statistically significant variation in the number of workers involved according to the posture (sitting vs standing) and part of the MSK system involved. Conclusion: The WMSD's are common in Adon block department workers. The involvement of neck, shoulder, lower back and arm was common in sitting position, while the involvement of upper back, elbow and knee were common in standing position. The disorders are commonly seen in workers irrespective of their duration of work and gender..
\end{abstract}

Keywords: Musculoskeletal disorders; Industry Workers; Nordic pain Questionnaire; Ahmednagar.

\section{INTRODUCTION}

The World Health Organization has characterized "work -related" diseases as multifactorial to indicate that several risk factors (e.g., physical, work organizational, psychosocial individual, and sociocultural) contribute to causing these diseases [1]. "Musculoskeletal disorders" include a wide range of inflammatory and degenerative conditions affecting the muscles, tendons, ligaments, joints, peripheral nerves, and supporting blood vessels. Musculoskeletal disorders (MSDs) are widespread in many countries, with substantial costs and impact on quality of life [2].

MSDs occur in certain industries and occupations with rates up to three or four times higher than the overall frequency. High-risk sectors include nursing facilities; air transportation; mining; food processing; leather tanning; and heavy and light manufacturing (vehicles, furniture, appliances, electrical and electronic products, textiles, apparel and shoes) [3]

Upper extremity musculoskeletal disorders are also highly prevalent in manual-intensive occupations, such as clerical work, postal service, cleaning, industrial inspection and packaging ${ }^{4}$. Back and lower limb disorders occur disproportionately among truck drivers, ware-

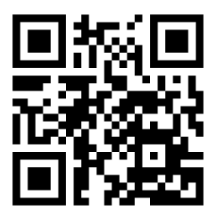

DOI: $10.31878 / \mathrm{ijcbr} .2019 .52 .08$

eISSN: 2395-0471

pISSN: 2521-0394 house workers, airplane baggage handlers, construction trades, nurses, nursing aides and other patient-care workers, and operators of cranes and other large vehicles $[4,5]$.

The present study was aimed to find out prevalence of the acute and chronic musculoskeletal disorders in Adon block department workers Larsen \& Toubro Industry, Ahmednagar.

\section{MATERIALS AND METHODOLOGY}

Study design: Descriptive cross-sectional study

Ethics approval: Ethical clearance was obtained from Institutional ethical committee, PDVVPF College of Physiotherapy. Written Informed consent was taken from all the participants.

Study period: The study was carried out during the period of October 2013 to January 2014.

Study population: The workers were subjected to inclusion and exclusion criteria before involving them in the study. Study undertaken in the Adon block department workers of Larsen \& Toubro Industry, Ahmednagar.

Inclusion criteria: Permanent workers of both gender of the age group between 21-60 years, willing to participate in the study were included in the study.

Exclusion criteria: Workers with previous history of

Correspondence: Dr. Sneha Chordiya, Assistant Professor, Department of Cardio-respiratory Physiotherapy, Anand Rishiji Hospital and Medical Research Center, Ahmednagar, MHS. Email: researchcell@pmtpims.org 
trauma or surgery, congenital deformity and those suffering from systemic illness like rheumatoid arthritis were excluded from the study.

Sample size: A total of 60 workers were selected from the workers by simple randomized sampling.

\section{Methodology:}

Pre-structured occupational Performa was filled by asking questions in worker's local language. The Nordic pain Questionnaire was filled by asking the subjects to mark the sites of pain on body chart paper [6].

The data collected were interpreted and Chi-squared test was applied for analysis

\section{RESULTS}

Table 1: Distribution of MSK disorders according to duration and part of MSK system involved

\begin{tabular}{|c|c|c|c|c|c|c|c|}
\hline & \multicolumn{3}{|c|}{ Acute } & \multicolumn{3}{|c|}{ Chronic } & \multirow[b]{2}{*}{$\begin{array}{l}\text { Grand } \\
\text { Total }\end{array}$} \\
\hline & $\frac{3}{2}$ & $\begin{array}{l}\overline{1} \\
\stackrel{0}{1} \\
0 \\
0\end{array}$ & $\begin{array}{l}\overrightarrow{0} \\
\vec{D} \\
\vec{D}\end{array}$ & $\frac{3}{0}$ & $\begin{array}{l}\bar{T} \\
0 \\
0 \\
0 \\
0\end{array}$ & $\begin{array}{l}\overrightarrow{0} \\
\stackrel{0}{D}\end{array}$ & \\
\hline Neck & 4 & $11^{\$}$ & 15 & $6^{8}$ & $17^{\# @}$ & $23^{*}$ & 38 \\
\hline Shoulder & 5 & 4 & 9 & 7 & 12 & 19 & 28 \\
\hline Elbow & 7 & 4 & 11 & 10 & 6 & 16 & 27 \\
\hline $\begin{array}{l}\text { Wrist/ } \\
\text { Hand }\end{array}$ & 4 & 5 & 9 & 5 & 7 & 12 & 21 \\
\hline $\begin{array}{l}\text { Upper } \\
\text { back }\end{array}$ & 3 & 4 & 7 & 5 & 8 & 13 & 20 \\
\hline $\begin{array}{l}\text { Lower } \\
\text { back }\end{array}$ & 3 & 6 & 9 & 3 & 6 & 9 & 18 \\
\hline Hip/Thigh & 3 & 2 & 5 & 3 & 1 & 4 & 9 \\
\hline Knee & 4 & 4 & 8 & 6 & 13 & 19 & 27 \\
\hline
\end{tabular}

* $\mathrm{P}=0.80$, Chi-squared Test for Independence, Acute vs Chronic ${ }^{\$} \mathrm{P}=0.65$, Chi-squared Test for Independence, Acute male vs Acute female

${ }^{\#} \mathrm{P}=0.32$, Chi-squared Test for Independence, Chronic male vs Chronic female

${ }^{\&} \mathrm{P}=0.99$, Chi-squared Test for Independence, Acute male vs Chronic male

${ }^{\circledR} \mathrm{P}=0.70$, Chi-squared Test for Independence, Acute female vs Chronic female

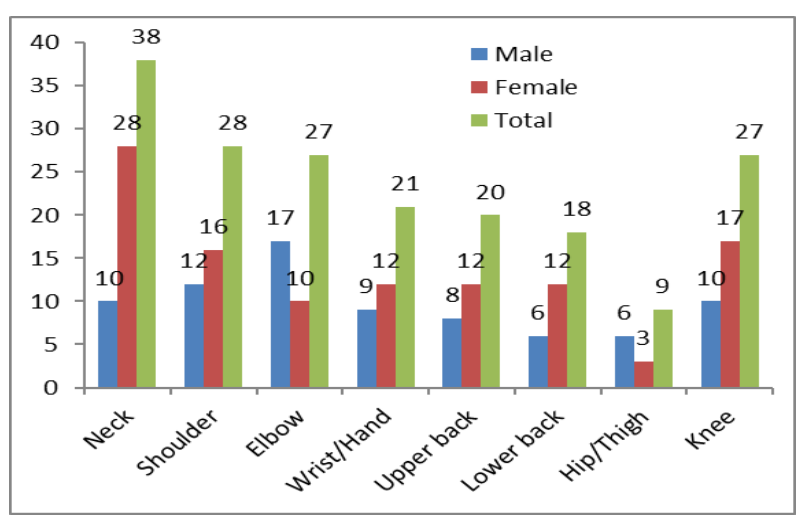

Fig 1: Distribution of MSK disorders according to gender and part of MSK system involved

In the present study, 60 workers were selected, of which number of females were $39(65 \%)$ while males were 21
(35\%). Table 1, Figure 1 display the distribution of MSK disorders according to duration and part of MSK system involved. The Neck $(20.2 \%)$ followed by shoulder $(14.9 \%)$, elbow $(14.4 \%)$ and knee $(14.4 \%)$ were most commonly involved. There was no statistically significant difference between the workers suffering from acute and chronic work related MSK disorders with respect to the part of MSK system involved. There was no statistical difference between gender of the workers and part of MSK system involved.

Table 2: Distribution of MSK disorders according to posture and part of MSK system involved.

\begin{tabular}{|c|c|c|c|c|c|c|c|}
\hline & \multicolumn{3}{|c|}{ Acute } & \multicolumn{3}{|c|}{ Chronic } & \multirow[b]{2}{*}{$\begin{array}{l}\overrightarrow{0} \\
0 \\
\stackrel{D}{D} \\
\tilde{D}\end{array}$} \\
\hline & $\frac{3}{0}$ & $\begin{array}{l}\bar{T} \\
0 \\
0 \\
0 \\
0 \\
0\end{array}$ & $\begin{array}{l}\overrightarrow{0} \\
\overrightarrow{0} \\
\vec{D}\end{array}$ & $\frac{3}{0}$ & $\begin{array}{l}\text { T) } \\
\stackrel{9}{0} \\
\stackrel{0}{0}\end{array}$ & $\overrightarrow{\vec{O}}$ & \\
\hline Neck & 4 & $11^{\$}$ & 15 & $6^{8}$ & $17^{\# @ ~}$ & $23 *$ & 38 \\
\hline $\begin{array}{l}\text { Shoul- } \\
\text { der }\end{array}$ & 5 & 4 & 9 & 7 & 12 & 19 & 28 \\
\hline Elbow & 7 & 4 & 11 & 10 & 6 & 16 & 27 \\
\hline $\begin{array}{l}\text { Wrist/ } \\
\text { Hand }\end{array}$ & 4 & 5 & 9 & 5 & 7 & 12 & 21 \\
\hline $\begin{array}{l}\text { Upper } \\
\text { back }\end{array}$ & 3 & 4 & 7 & 5 & 8 & 13 & 20 \\
\hline $\begin{array}{l}\text { Lower } \\
\text { back }\end{array}$ & 3 & 6 & 9 & 3 & 6 & 9 & 18 \\
\hline $\begin{array}{l}\text { Hip/ } \\
\text { Thigh }\end{array}$ & 3 & 2 & 5 & 3 & 1 & 4 & 9 \\
\hline Knee & 4 & 4 & 8 & 6 & 13 & 19 & 27 \\
\hline
\end{tabular}

* $\mathrm{P}=0.006$, Chi-squared Test for Independence, sitting vs Standing. ${ }^{\#} \mathrm{P}=0.6569$, Chi-squared Test for Independence, sitting acute vs Sitting chronic

${ }^{\$} \mathrm{P}=0.99$, Chi-squared Test for Independence, standing acute vs Standing chronic

${ }^{@} \mathrm{P}=0.21$, Chi-squared Test for Independence, sitting acute vs Standing acute

${ }^{\%} \mathrm{P}=0.13$, Chi-squared Test for Independence, sitting chronic vs Standing chronic

Table no. 2 displays distribution of MSK disorders according to posture and part of MSK system involved, in which, most predominant was neck $(24.2 \%)$ followed by back $(18.8 \%)$, hands $(16.4 \%)$. There was statistically significant variation in the number of workers involved according to the posture (sitting vs standing) and part of MSK system involved. However, no statistical significance was seen when the duration of MSK disorder (Acute vs Chronic) was considered in between and among sitting and standing workers, respectively.

\section{DISCUSSION}

In the present study the work related acute and chronic musculoskeletal disorders are prevalent in the neck and upper limbs because of awkward posture that they assume during the work (Table no. 2). There was no statistically significant difference in the gender, duration of MSD with respect to the part of the MSK system involved (Table no.1). But when the correlation of part of the MSK system involved were compared with the working posture of the workers, highly significant difference $(\mathrm{p}=0.006)$ was observed (Table no. 2$)$.

Similar studies done by Roquelaure et al. On clinical 
diagnosis and epidemiological study of the musculoskeletal disorders of the upper extremities among a sample of employees in France and reported that the prevalence rate of musculoskeletal disorders of the upper extremities among male employees in steel manufacturing was $14.8 \%$, which was the second highest following automobile manufacturing (20.0\%) [5]. MoussaviNajarkola et al. examined the upper extremities in terms of musculoskeletal symptoms and diseases among the employees of a steel company in Tehran who were exposed to high force exertion, repetition, and awkward postures, using a standardized Nordic Musculoskeletal Questionnaire and clinical examinations. According to their results, the symptom prevalence was $66-88 \%$ and disease prevalence was $5.4-18.7 \%$ [6].

S Arun Vijay [7] et al studied-on Work Related Musculoskeletal Disorders among Information Technology Professionals in India and concluded that WRMSDs are widely reported by the IT professionals working in the IT industries in India and 59\% of them reported that they had experienced some form of musculoskeletal health symptoms in the past 12 months. Neck pain problems were the most frequently reported followed by Lower back, wrists and hands, and shoulder problems.

WMS Johnson et al [8] studied Prevalence MSDs in workers in an industrial town in Tamil Nadu and found that the overall prevalence of MSD was $32.6 \%$. J N Katz et al [9] in a one-year follow-up study in automobile manufacturing workers found that about $10 \%$ of participants without symptoms or physical examination findings at baseline developed new disorders within a period of about one year. Nurhayati Mohd Nur [10] studied The Prevalence of work-related Musculoskeletal Disorders Among Workers in the Automotive Manufacturing Companies and found highest prevalence of MSDs for the last twelve months is on the neck, followed by hand/wrist, shoulder and upper back. Pandey et al [11] studied work related MSDs of workers In Brick making factories of Uttar Pradesh they suffered from discomfort and pain in different parts of their body, specifically in neck, back, knees, and elbow regions. Kaergaard A et al [12] studied prevalence in MSDs of the neck and shoulders in female sewing machine operators: Rotator cuff tendinitis showed a higher degree of persistence than myofascial pain syndrome.

In our study, the involvement of neck, shoulder, lower back and arm was common in sitting position. Also, involvement of upper back, elbow and knee was common in standing position. Thus, the disorders are commonly seen in workers irrespective of their duration of work and gender. Also, the type of MSD is related to the posture acquired during the working hours. These awkward postures place high demands on musculoskeletal system which is consistent with daily work and results in musculoskeletal disorders. A change in posture after repeated intervals decreases the continuous strain on one part of MSK system.

The shortcomings of the study were smaller sample size and involvement of only one department of workers in the company. Further study with larger sample size and involvement of all departments is desirable.

Anas Ali et al [13] carried out study in workers working in typical Indian saw mills and found that unawareness about ergonomics is observed in industry in which work is undertaken. Habibullah N Saiyed [14] et al found that poor implementation of control measures and enforcement of laws and concluded that awareness and health education programme should be carried out for the workers, supervisors and owners/management of the factories/mines engaged in hazardous process. Possible economic benefits resulting from prevention programs must be aced before the management, trade unions and policy makers. Rwamamara et al [15] found that a range of generic issues or aspects such task design (at the planning stage), worker/equipment interface, individual variation, training needs, work organization and legal requirement should be considered.

\section{CONCLUSION}

The work-related MSD's are common in industry workers. The involvement of neck, shoulder, lower back and arm was common in sitting position. Also, involvement of upper back, elbow and knee was common in standing position. The disorders are commonly seen in workers irrespective of their duration of work and gender.

Conflict of Interest: Declared none

\section{REFERENCES}

[1] John CR, Thomas MC. Upper Extremity Musculoskeletal Disorders: Occupational Association and a Model for Prevention. CEJOEM 1998; 4(3):21431

[2] Punnett L, Wegman DH. Work-related musculoskeletal disorders: The epidemiologic evidence and the debate. Journal of Electromyography and Kinesiology 2004;14:13-23

[3] Badley EM, Rasooly I, Webster GK. Relative importance of musculoskeletal disorders as a cause of chronic health problems, disability, and health care utilization: findings from the 1990 Ontario Health Survey. J Rheumatol 1994 ;21(3):505-14

[4] Keyserling WM. Ergonomic job analysis: a structured approach for identifying risk factors associated with overexertion injuries and disorders. Applied Occupational and Environmental Hygiene, 1991;6(5): 15.

[5] Roquelaure Y, Ha C, Leclerc A. Epidemiologic surveillance of upper-extremity musculoskeletal disorders in the working population. Arthritis Rheum 2006;55:765-78.

[6] Moussavi-Najarkola SA, Khavanin A. Work related musculoskeletal disorders of the upper limbs among steel industry populations. Acta Medica Iranica 2007;45: 405-14.

[7] Arun Vijay. Work Related Musculoskeletal Disorders among Information Technology Profesionals in India. International Journal of Management Research and Business Strategy. 2013;2: 118-28.

[8] Johnson. Prevalence of Upper Extremity Musculoskeletal Disorders among workers in an industrial town in Tamilnadu, Journal of Clinical and Diagnostic Research. 2011 ;5(2):187-19.

[9] Katz JN. Ergonomic stressors and upper extremity 
musculoskeletal disorders in automobile manufacturing, Occup Environ Med 2004 ;61 :668-74

[10] Nurhayati Mohd Nur. The Prevalence of Work Related Musculoskeletal Disorders Among Workers Performing Industrial Repetitive Tasks in the Automotive Manufacturing Companies, Proceedings of the 2014 International Conference on Industrial Engineering and Operations Management Bali, Indonesia, 2014;Jan 7 - 9

[11] Pandey K. Work-related musculoskeletal disorders of workers in brick making factories of Uttar Pradesh-an ergonomic approach. International Journal of Advanced Engineering Technology. 2012;3 (1):121-5

[12] Anette Kaergaard. Musculoskeletal disorders of the neck and shoulders in female sewing machine operators: prevalence, incidence, and prognosis, Occup Environ Med 2000;57:528-34

[13] Anas Ali. An ergonomic study of work related musculoskeletal disorders among the workers working in typical Indian saw mills, International Journal of Engineering Research and Development. IJERD 2012; 3(9): 38-45

[14] Habibullah N Saiyed. Work-related musculoskeletal disorders: the epidemiologic evidence and the debate, Journal of Electromyography and Kinesiology, 2004;14:13-23

[15] Rwamamara RA. Evidence-Based Prevention Of Work-Related Musculoskeletal Injuries In Construction Industry, Journal of civil engineering and management 2010;16(4): 499-509 